\title{
Trends in Outcome and Hospitalization Charges of Adult Patients Admitted with Botulism in the United States
}

\author{
Nizar Souayah $^{a}$ Lubna Shafiq Mehyar ${ }^{a}$ Hafiz M.R. Khan ${ }^{b}$ Hussam A. Yacouba \\ Zaid Abed Al-Kariem A Al-Qudah ${ }^{\mathrm{a}}$ Abu Nasar ${ }^{\mathrm{C}}$ Zubeda Begum Sheikh ${ }^{\mathrm{a}}$ \\ Leila Maybodia Adnan I. Qureshi $^{\mathrm{d}}$ \\ ${ }^{a}$ Department of Neurology, University of Medicine and Dentistry of New Jersey, Newark, N.J., b Department of \\ Biostatistics, Robert Stempel College of Public Health and Social Work, Florida International University, Miami, \\ Fla., 'Division of Thoracic Surgery, Department of Cardiothoracic Surgery, Weill Cornell Medical College, New York \\ Presbyterian Hospital, New York City, N.Y., and d Zeenat Qureshi Stroke Research Center, University of Minnesota, \\ Minneapolis, Minn., USA
}

\section{Key Words}

Botulism · Hospitalization charges · Mechanical ventilation • Length of hospitalization $\cdot$ Mortality

\section{Abstract \\ Background: To assess the impact of new therapeutic strat- egies on outcomes and hospitalization charges among adult patients with botulism in the United States. Methods: We determined in-hospital outcomes and charges for patients with botulism hospitalized in 1993-1994 and compared them with those observed among patients hospitalized in 2006-2007. Mortality, length of stay, and hospitalization charges were calculated. Age, sex, race, ethnicity, and dis- charge status were also reported. Results: There were 66 and 132 admissions of adult patients with botulism in 1993- 1994 and 2006-2007, respectively. Men predominance was observed in 2006-2007 compared to women predominance during the 1993-1994 time period. There was no significant difference in the average length of stay and in-hospital mor- tality rate between the two groups studied. However, in the 2006-2007 group, there was a significant increase in the}

mean hospitalization charges (USD 126,092 $\pm 120,535$ vs. USD $83,623 \pm 82,084 ; p=0.0107$ ) and in the proportion of patients requiring mechanical ventilation when compared to $1993-1994$ (34 vs. $13.6 \%$; $p<0.0001$ ). Conclusion: Botulism continues to be an infrequent cause of hospitalization, with a significant increase in the average hospitalization charges in 2006-2007 when compared to 1993-1994, despite a nonsignificant change in the mortality rate and average length of hospitalization.

Copyright $\odot 2012$ S. Karger AG, Basel

\section{Introduction}

Botulism is an acute life-threatening neurological disorder that is caused by a neurotoxin produced by Clostridium botulinum. The main etiologies of adult botulism include foodborne botulism, wound botulism, and, rarely, botulism acquired by inhalation [1]. In addition, there is an increase in reported cases of iatrogenic botulism and botulism acquired by drug users [2]. In the United States, the mortality rate among patients with botulism reached

\section{KARGER}

Fax +4161306 1234

E-Mail karger@karger.ch

www.karger.com (c) 2012 S. Karger AG, Basel

0251-5350/12/0384-0233\$38.00/0

Accessible online at:

www.karger.com/ned
Nizar Souayah, MD

Department of Neurology

University of Medicine and Dentistry of New Jersey

90 Bergen Street, DOC 8100, Newark, NJ 07103 (USA)

Tel. +1 973972 8577, E-Mail souayani@umdnj.edu 
Table 1. The demographics, clinical characteristics, and in-hospital outcomes among patients hospitalized with botulism in the United States (NIS 1993-1994 and 2006-2007)

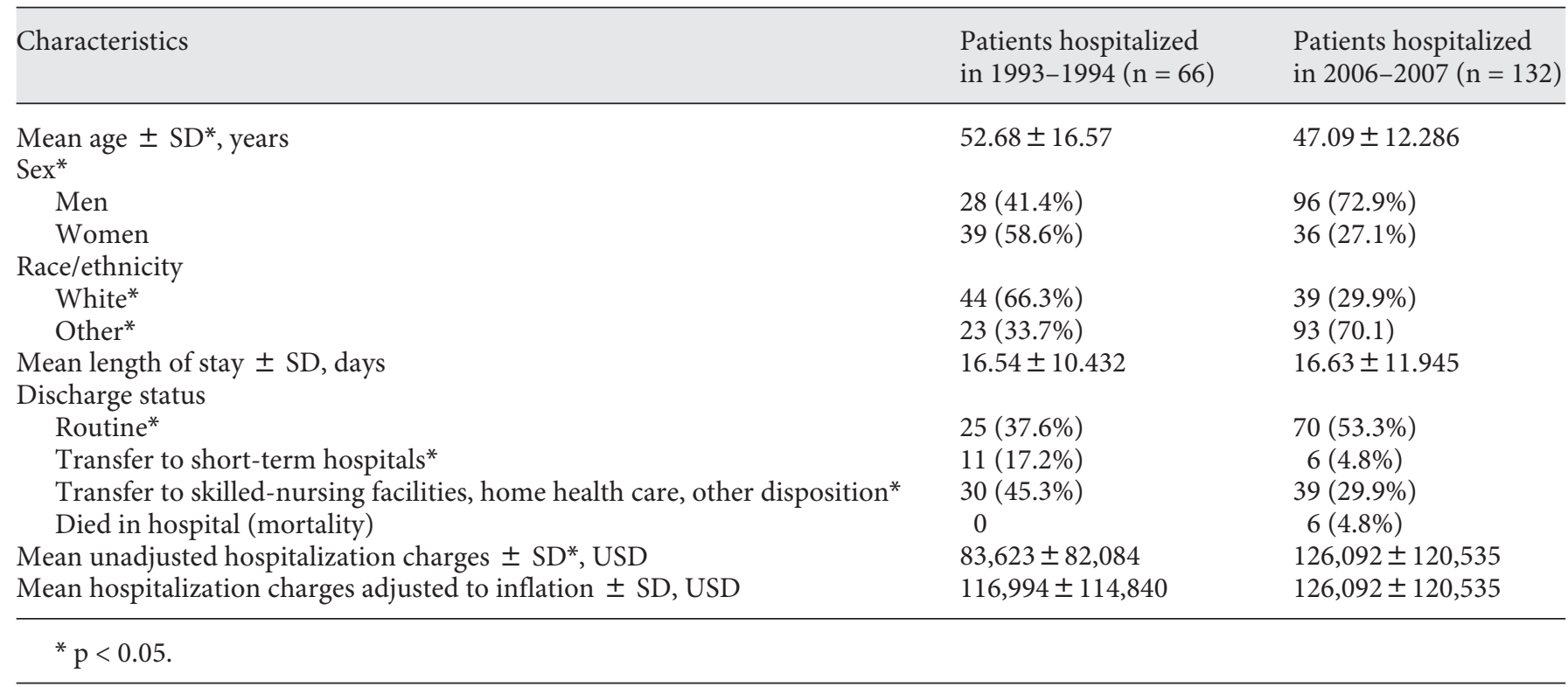

$60-70 \%$ during the first decades of the 20th century, the era before mechanical ventilation [1]. With the improvement in mechanical ventilation techniques, intensive supportive care, and the availability of therapies with equine antitoxins, the mortality rate from botulism has steadily decreased to a range of only $3-5 \%[1,3]$. Over the past two decades, new advances in the management of botulism have led to a more effective use of equine antitoxins and improved methods of pulmonary support and mechanical ventilation [4-6]. Most of the new supportive care modalities for botulism were not available in 1993-1994, whereas in 2006-2007 several strategies, including specialized intensive care units, more effective immunotherapies, and noninvasive bi-level ventilation (BiPAP), were widely available $[4,5]$. The aim of this study is to assess the impact of new therapeutic strategies on adult patients with botulism by studying changes in hospital outcomes and hospitalization charges over a period of 13 years.

\section{Methods}

We used data from the Nationwide Inpatient Sample (NIS), sponsored by the Agency for Healthcare Research and Quality. The NIS is the largest inpatient all-payer database in the United States that is designed to identify, track, and analyze national trends in health care utilization, access, charges, quality, and outcome. The NIS database includes data on more than 100 clinical and nonclin- ical variables associated with hospital stays, including primary and secondary diagnoses, primary and secondary procedures, patients' admission and discharge status, patient demographic information, expected payment source, total charges, and length of stay. We identified adult patients (age $>18$ years) with a primary diagnosis of botulism using the International Classification of Disease, 9th Revision, Clinical Modification code 005.1. We then reviewed the hospitalization characteristics of adult patients with botulism in 1993-1994 and 2006-2007. We compared the demographic characteristics, number of admissions, hospitalization outcome, and charges incurred among patients hospitalized with adult botulism in the two time periods. We used the SPSS 17 software program to convert raw counts generated from the NIS database into weighted counts that were used to generate national estimates. SPSS 17 procedures were also used to analyze the data. Finally, we used two independent samples t tests for continuous data and two independent samples proportion tests for categorical data.

The effect of inflation on hospital charges was adjusted using the US Bureau of Labor Statistics' Consumer Price Index (www. bls.gov/cpi).

\section{Results}

\section{Demographic and Clinical Characteristics}

The demographic and clinical characteristics of the patients hospitalized with botulism in 1993-1994 and 2006-2007 are shown in table 1 . The average age \pm standard deviation (SD) was significantly higher in 1993 1994 compared to $2006-2007$ (52.68 \pm 16.57 vs. $47.1 \pm$ 
12.3 years, respectively; $\mathrm{p}=0.0081$ ). The proportion of women was significantly higher than that of men in 1993-1994 [39 (58.6\%) vs. 28 (41.4\%); p < 0.0001], whereas in 2006-2007, there was a significantly higher predominance of men [96 (72.9\%) vs. $36(27.1 \%) ; \mathrm{p}<0.0001]$. The racial/ethnic distribution of patients showed a predominance of Caucasian patients in 1993-1994, while a predominance of other ethnicities, including Asian, Latino, and Native American patients, was noted in 2006-2007 (table 1). Although the US population became more diverse in 2006-2007 (approx. 83.2\% Caucasian and 16.8\% other ethnicities in 1993-1994, vs. 79.26\% Caucasian and 20.64\% other ethnicities in 2006-2007), these changes in US demographics did not parallel the ethnic distribution of botulism cases.

\section{In-Hospital Outcomes}

The average length of hospitalization $( \pm S D)$ in both time periods was comparable: $16.54 \pm 10.43$ days in 1993-1994 versus $16.63 \pm 11.9$ days in 2006-2007 (table 1). The in-hospital mortality rate was $4.8 \%$ in $2006-$ 2007 and $0 \%$ in 1993-1994, which was not statistically significantly different $(\mathrm{p}=0.079)$. The number of routine discharges was significantly lower in 1993-1994 (37.6\%) than that observed in 2006-2007 (53.3\%; p < 0.005). The number of patients transferred to short-term hospitals was significantly higher in $1993-1994$ (17.2 vs. $4.8 \%$; $\mathrm{p}=$ $0.004)$. The number of patients transferred to skilled-nursing facilities, other institutions, or with home health care was also higher in 1993-1994 (45.3 vs. 29.9\%; p = $0.03)$. There was a substantial increase in the proportion of patients requiring mechanical ventilation in 20062007 compared to $1993-1994$ (34.8 vs. $13.6 \%$; $\mathrm{p}<0.0001$ ).

\section{Total Hospitalization Charges}

The mean hospitalization charge for each patient was significantly higher in 2006-2007 when compared to 1993-1994 (USD 126,092 $\pm 120,535$ vs. USD 83,623 \pm 82,084 , respectively; $\mathrm{p}=0.0107$ ), even after adjusting for inflation (table 1).

Therefore, over a span of 13 years (between 1993-1994 and 2006-2007), our data analysis revealed that patients with adult botulism were predominantly men in 20062007 compared to predominantly women in 1993-1994. There was no significant difference in the average length of stay and in-hospital mortality rate between the two groups studied. However, in the 2006-2007 group, there was a significant increase in the mean hospitalization charges (USD 126,092 $\pm 120,535$ vs. USD 83,623 \pm 82,084; $\mathrm{p}=0.0107$ ) even after adjustment for inflation

Outcome and Hospitalization Charges of

Adult Botulism (table 1) and in the proportion of patients requiring mechanical ventilation when compared to 1993-94 (34 vs. $13.6 \%$; $<<0.0001)$.

\section{Discussion}

Although adult botulism is relatively rare, its incidence has been rising since the early 1990s [1, 7, 8]. A total of 1,022 cases of botulism were reported to the Center for Disease Control (CDC) between 2001 and 2007, of which 359 involved adult patients. Wound botulism was exceedingly rare until the mid-1980s and exclusively related to deep tissue infections in avascular body locations [8]. Since that time, a dramatic and continuous increase in the incidence of wound botulism was observed in the United States, which became the most frequent form of adult botulism [8] and was almost exclusively associated with injection drug use [7-9]. Prolonged mechanical ventilation and intensive care unit admissions were more common in such cases [8]. This explains the substantial increase in the mean hospitalization cost and the number of mechanically ventilated patients in the 2006-2007 group.

The improvement in the outcomes of adult botulism is largely related to the development of modern intensive care techniques, mechanical ventilation, and other methods of pulmonary support such as noninvasive ventilation [4-6, 10-13]. Although there were no significant changes in botulism antitoxin formulation or in the indication for administration, the 2- to 4-fold decrease in the antitoxin dose since 1996 reduced the incidence of hypersensitivity reactions from $9 \%$ to less than $1 \%[1,14]$. These changes in intensive care practice and adult botulism management may explain the stabilization of the average length of hospital stay and mortality rate in the two time periods, despite the increase in the proportion of mechanically ventilated patients in 2006-2007. Further, due to the social status of patients with botulism related to injection drug use, the length of hospital stay and cost may be affected by other nonmedical variables such as the availability of home care and rehabilitation facilities. These nonmedical factors could mask a potential reduction in the average length and cost of hospitalization related to improved hospital care in the 2006-2007 time period.

In summary, the significant increase in the average hospitalization charges for botulism, without significant changes in mortality and average length of hospital stay, could be related to the significant increase in the number of mechanically ventilated patients in 2006-2007, as compared to the 1993-1994 time period.

Neuroepidemiology 2012;38:233-236 


\section{References}

1 Sobel J: Botulism. Clin Infect Dis 2005;41: 1167-1173.

- 2 Souayah N, Karim H, Kamin SS, McArdle J, Marcus S: Severe botulism after focal injection of botulinum toxin. Neurology 2006;67: 1855-1856.

3 Hughes JM, Blumenthal JR, Merson MH, Lombard GL, Dowell VR Jr, Gangarosa EJ: Clinical features of types A and B food-borne botulism. Ann Intern Med 1981;95:442-445.

4 Mayer SA: Neurological intensive care: emergence of a new specialty. Neurocrit Care 2006;5:82-84.

5 Mayer SA, Coplin WM, Chang C, Suarez J, Gress D, Diringer MN, Frank J, Hemphill JC, Sung G, Smith W, Manno EM, Kofke A, Lam A, Steiner T, Neurocritical Care Society, American Academy of Neurology Section on Critical Care and Emergency Neurology, Society of Neurosurgical Anesthesia and Critical Care: Core curriculum and competencies for advanced training in neurological intensive care: United Council for Neurologic Subspecialties guidelines. Neurocrit Care 2006;5:159-165.
6 Bach JR: A historical perspective on the use of noninvasive ventilatory support alternatives. Respir Care Clin N Am 1996;2:161181.

7 Werner SB, Passaro D, McGee J, Schechter R, Vugia DJ: Wound botulism in California, 1951-1998: recent epidemic in heroin injectors. Clin Infect Dis 2000;31:1018-1024.

8 Offerman SR, Schaefer M, Thundiyil JG, Cook MD, Holmes JF: Wound botulism in injection drug users: time to antitoxin correlates with intensive care unit length of stay. West J Emerg Med 2009;10:251-256.

-9 Passaro DJ, Werner SB, McGee J, Mac Kenzie WR, Vugia DJ: Wound botulism associated with black tar heroin among injecting drug users. JAMA 1998;279:859-863.
10 Bach JR: Update and perspective on noninvasive respiratory muscle aids. Part 2 . The expiratory aids. Chest 1994;105:1538-1544.

11 Bach JR: Update and perspectives on noninvasive respiratory muscle aids. Part 1 . The inspiratory aids. Chest 1994;105:1230-1240.

12 Bach JR, Saporito LR: Indications and criteria for decannulation and transition from invasive to noninvasive long-term ventilatory support. Respir Care 1994;39:515-528; discussion 529-531.

13 Bach JR, Saporito LR: Criteria for extubation and tracheostomy tube removal for patients with ventilatory failure. A different approach to weaning. Chest 1996;110:15661571.

14 Shapiro RL, Hatheway C, Swerdlow DL: Botulism in the United States: a clinical and epidemiologic review. Ann Intern Med 1998; 129:221-228. 